Editorial

\title{
Revista Acta Colombiana de Psicología
}

\author{
Ernesto L. Ravelo-Contreras*
}

Con el presente vol. 22 n. ${ }^{\circ} 2$ (2019) de Acta Colombiana de Psicología se cumplen veintidós años de edición periódica continua, y se presentan 14 artículos pertenecientes a las áreas de Psicología de la salud, Neuropsicología, Psicología educativa, Psicología básica, Psicometría y Psicología de la percepción.

Para iniciar, desde el área de la Psicología de la salud aparecen dos artículos: el primero, con metodología de tipo correlacional, cuyo objetivo es establecer la relación entre la gaudibilidad y la percepción del estado de salud en una muestra de 285 mexicanos de entre 14 y 78 años; y el segundo, un estudio comparativo transcultural en una muestra estratificada no aleatorizada de 1603 hombres y mujeres adolescentes y jóvenes escolarizados (870 chilenos y 732 colombianos) para identificar las diferencias en las creencias relacionadas con el consumo de alcohol y comparar las medias entre los países (con el uso del estadístico ANOVA).

A continuación, desde la Neuropsicología se contribuye con un estudio sobre los Signos Neurológicos Blandos (SNB) en el que se evaluó la presencia de SNB y su relación con algunos procesos cognitivos en 144 participantes de estrato socioeconómico medio-bajo (sin antecedentes neurológicos o psiquiátricos) con edades de 6 a 11 años, por medio del Cuestionario de madurez neuropsicológica infantil (CUMANIN) y el Cuestionario de madurez neuropsicológica escolar (CUMANES).

Posteriormente, desde la Psicología educativa se presentan seis trabajos: en un primer estudio, el objetivo fue determinar la existencia de estereotipos negativos hacia la vejez en 262 estudiantes de carreras universitarias relacionadas y no relacionadas con el campo de la salud; para esto, se aplicó el cuestionario CENVE y se realizó un análisis ANOVA y comparaciones post hoc según su titulación. En un segundo estudio, se muestra la relación entre los estilos parentales disfuncionales y la empatía en 599 estudiantes de ambos sexos, con edades entre los 21 y 25 años, según su carrera profesional (Enfermería, Medicina Humana y Psicología). En un tercer estudio, el objetivo fue identificar, en una muestra de 986 alumnos de entre 16 y 40 años de diferentes carreras de dos universidades, las diferencias entre hombres y mujeres en cuanto a la influencia de las dimensiones de personalidad sobre la procrastinación académica. En el cuarto trabajo, de tipo correlacional y con diseño transversal, se estableció la relación entre el compromiso social (en sus dimensiones de contacto, apoyo y conflicto social) y algunos procesos cognitivos (flexibilidad mental, planeación, fluidez verbal, velocidad de procesamiento y comprensión verbal) en 49 jóvenes universitarios. En el quinto trabajo, por medio de un método historiográfico y a partir de los análisis realizados por Michel Foucault hacia mediados de la década de 1970 con respecto al surgimiento de un poder disciplinario en occidente y la figura del "débil mental" en el ámbito educativo que impulsan la aparición de elaboraciones teóricas y modalidades de intervención denominadas como "función psi", se retoman cuestiones históricas relevantes con el fin de indagar el despliegue de los saberes y prácticas psicológicas que se ocupan de los niños que no logran adaptarse a las normas del dispositivo escolar en Chile. Y, por último, en un sexto estudio, se tuvo como objetivo analizar la configuración del sentido de la profesión académica en 160 profesores universitarios pertenecientes a universidades públicas y privadas de cinco ciudades colombianas, por medio del instrumento QPW-5 (Cuestionario sobre calidad de vida laboral en organizaciones de servicios humanos).

Asimismo, desde la Psicología básica se puede encontrar un estudio experimental, con tres experimentos con diseños mixtos, que investigó el efecto del estatus social (ES) en la distribución de los recursos monetarios en estudiantes de 18 a 25 años: en el Experimento 1 se comparó el efecto de dos técnicas de manipulación del ES en las decisiones del Juego del Ultimátum (JU) y del Dictador (JD); en el Experimento 2 se analizó el efecto del ES en los mismos juegos, incluyendo la orientación de valores sociales (SVO) y el estatus social subjetivo (SES) como covariables; y en el Experimento 3 se indagó el rol del ES, de la SVO y del ESS en el JD y en el Dictador de Tomar (JDT).

Editor. revistaacta@ucatolica.edu.co; orcid.org/0000-0002-9565-0828 
Por otra parte, se presentan tres investigaciones en área de Psicometría: en primer lugar, un estudio para diseñar y validar la Escala de actitudes maternas hacia el sobrepeso y la obesidad infantil; posteriormente, una investigación que tuvo como objetivo analizar las propiedades psicométricas del Cuestionario de resiliencia para niños y adolescentes en una muestra de 512 estudiantes; $y$, seguidamente, un estudio en el que se analizaron las propiedades psicométricas (evidencias de validez y confiabilidad) de la Escala de niveles y condiciones de Aprendizaje organizacional (ENCAO) en 384 trabajadores de una empresa privada.
Y, por último, desde el área de la Psicología de la Percepción se presenta una investigación que tuvo como finalidad analizar las divergencias entre la percepción de las prácticas parentales, el comportamiento positivo y las problemáticas entre padres e hijos, en una muestra compuesta por diadas de 248 padres-hijos, 241 padres-hijas, 237 madres-hijos y 241 madres-hijas, por medio de la Escala de capacidades y dificultades y la Escala de prácticas parentales. 